\title{
Effect of surface organic coatings of cellulose nanocrystals on the viability of mammalian cell lines
}

This article was published in the following Dove Press journal:

Nanotechnology, Science and Applications

28 September 2017

Number of times this article has been viewed

\author{
Ambar S Jimenez' \\ Francesca Jaramillo' \\ Usha D Hemraz ${ }^{2}$ \\ Yaman Boluk ${ }^{3}$ \\ Karina Ckless' \\ Rajesh Sunasee' \\ 'Department of Chemistry, State \\ University of New York at Plattsburgh, \\ Plattsburgh, NY, USA; ${ }^{2}$ National \\ Research Council, Montreal, QC, \\ Canada, ${ }^{3}$ Department of Civil \& \\ Environmental Engineering, University \\ of Alberta and National Institute for \\ Nanotechnology, National Research \\ Council, Edmonton, AB, Canada
}

\begin{abstract}
Cellulose nanocrystals (CNCs) have emerged as promising candidates for a number of bio-applications. Surface modification of CNCs continues to gain significant research interest as it imparts new properties to the surface of the nanocrystals for the design of multifunctional CNCs-based materials. A small chemical surface modification can potentially lead to drastic behavioral changes of cell-material interactions thereby affecting the intended bio-application. In this work, unmodified CNCs were covalently decorated with four different organic moieties such as a diaminobutane fragment, a cyclic oligosaccharide ( $\beta$-cyclodextrin), a thermoresponsive polymer (poly[ $N$-isopropylacrylamide]), and a cationic aminomethacrylamide-based polymer using different synthetic covalent methods. The effect of surface coatings of CNCs and the respective dose-response of the above organic moieties on the cell viability were evaluated on mammalian cell cultures (J774A.1 and MFC-7), using 3-(4,5-dimethylthiazol-2-yl)-2,5-diphenyltetrazolium bromide and lactate dehydrogenase assays. Overall, the results indicated that cells exposed to surface-coated CNCs for $24 \mathrm{~h}$ did not display major changes in cell viability, membrane permeability as well as cell morphology. However, with longer exposure, all these parameters were somewhat affected, which appears not to be correlated with either anionic or cationic surface coatings of CNCs used in this study.
\end{abstract}

Keywords: cellulose nanocrystals, surface coating, cell viability, MTT, LDH

\section{Introduction}

With the rapid development of nanoscience and nanotechnology, cellulose has revived in the form of nanocelluloses with a pressing demand for their large-scale production for various potential high-end sustainable applications in diverse fields such as materials science, biomedicine, electronics, catalysis etc. ${ }^{1,2}$ Among the family of the nanocelluloses are cellulose nanocrystals (CNCs), which have recently gained significant interest in both academic and industrial research. CNCs are nanoscale-sized, needle- or rod-like particles typically derived from the acid hydrolysis of native cellulose under controlled conditions. Their high mechanical strength and unique physicochemical properties made them attractive building blocks for the development of new functional cellulose-based nanomaterials. ${ }^{3-5}$ Other than their perceived use in high-performance nanocomposites, CNCs have turned into promising materials for biomedical applications due to their special surface chemistry, environmental biodegradability, biocompatibility and low toxicity. ${ }^{6,7}$ The exposure to CNCs via occupational, environmental, consumer and biomedical arenas is expected to increase rapidly given the high interest in the large-scale production of CNCs (particularly wood-based CNCs) in order to

Tel +I $5185644 \mid 18$

Email kckle00I@plattsburgh.edu 
meet both academic and industrial research demands. CNCs possess high aspect ratio and stiffness similar to asbestos and carbonaceous fibers that have been linked with high toxicity. ${ }^{8}$ As such, recent efforts have focused on evaluating the health effects associated with CNCs exposures given the wide potential applications of CNCs in the biomedical fields such as drug and gene delivery, bioimaging, biosensing, tissue engineering and enzyme/protein immobilization scaffolds. ${ }^{9}$ A recent review by Roman provides a detailed account on current literature on the pulmonary, oral, dermal and cytotoxicity of CNCs, which highlighted the importance of careful sample characterization and the exclusion of the interfering effects of endotoxins and cytotoxic contaminants during the assessment of the potential adverse health effects of CNCs. ${ }^{10}$ Shatkin and Kim proposed a life cycle risk assessment (LCRA) framework called NANO LCRA that was employed for pre-commercial screening of selected applications of nanocelluloses (CNCs and cellulose nanofibrils). This systematic method identified and assessed the potential risks of nanocelluloses from occupational, consumer and environmental exposures throughout the product life cycle. ${ }^{11}$ Camarero-Espinosa et al discussed the importance of how knowledge gained from studying the biological impact of other nanomaterials could provide a basis for future research strategies to assess the human health risks that could arise from the use of CNCs. ${ }^{12}$ With regard to the evaluation of the cytotoxicity effects of CNCs, several studies have been carried out using CNCs obtained from different cellulosic sources, preparation procedures as well as with a variety of cell lines. ${ }^{13-25}$ Most of these studies indicated CNCs to be non-toxic at low concentrations, while a few studies showed a dose-dependency of CNCs cytotoxicity. ${ }^{14,18,20,24,25}$ Discordant results of CNCs cytotoxicity have also been reported, which could likely be caused by variations in experimental procedures, composition and size of nanoparticles employed, use of varying cellulosic sources and cell types. ${ }^{14,24}$ While a number of studies have focused mainly on the cytotoxicity of unmodified CNCs and/or fluorescently-labeled CNCs, there are still very limited data regarding the cytotoxicity assessment of surface-modified CNCs, in particular, CNCs coated with structurally functional organic materials for diverse bioapplications. ${ }^{15,22,26}$ Surface modification of CNCs is crucial for the synthesis of advanced and multifunctional CNCs-based materials and as such, it has been a subject of intense research in the past few years. ${ }^{27-29}$ However, a small chemical modification can potentially lead to drastic behavioral changes of cell-material interactions. It is therefore crucial to evaluate the risks associated with surface-modified CNCs before the latter can be fully exploited for the intended bio-application. Herein, the objective of this study is to synthesize and assess the cytotoxicity of 4 modified CNCs having different surface molecular architectures (ranging from a simple organic moiety to complex polymeric structures) and surface charges (anionic and cationic). In this work, the surface of CNCs was covalently decorated with different functional moieties such as a diaminobutane fragment, a cyclic oligosaccharide ( $\beta$-cyclodextrin $[\beta$-CD]), a thermoresponsive polymer (poly(N-isopropylacrylamide)(poly[NIPAAm])), and a cationic aminomethacrylamide-based polymer to generate CNCs with 4 distinct modified surfaces, termed as CNCs-AMINE, CNCs- $\beta$-CD, CNCs-poly(NIPAAm), and CNCs-poly( $N$-[3-aminopropyl]methacrylamide [APMA]) (Scheme 1). The choice of the above grafted materials is based on their potential use in the biomedical field and to the best of our knowledge, this is the first report of their detailed toxic effects in mammalian cell lines such as J774A.1 (mouse monocyte cells) and MCF-7 (human breast adenocarcinoma cells). In-vitro studies are rapid and cost-effective means to assess cytotoxicity of materials and select the most effective ones for further studies in vivo.

\section{Experimental materials}

For the purpose of this work, CNCs was obtained from Innotech Alberta (previously Alberta Innovates Technology Futures), a research institute based in AB, Canada. The fibers were prepared by subjecting Whatman ${ }^{\mathrm{TM}}$ cotton filter paper to acid hydrolysis using concentrated sulfuric acid. A detailed preparation method is described elsewhere. ${ }^{30}$ Acetone, copper (I) bromide, $\beta$-cyclodextrin, deuterium oxide, 1,3-diaminopropane, epichlorohydrin (99\%), ethanol, hydrochloric acid, hydroquinone, methacrylic anhydride, methanol, $N, N, N^{\prime}, N^{\prime \prime}, N^{\prime \prime}$-pentamethyldiethylenetriamine (PMDETA), 2-propanol and tetrahydrofuran (99\%) were obtained from Sigma-Aldrich (St. Louis, MO, USA). Uranyl acetate (dihydrate, 99.6\%) and transmission electron microscopy (TEM) grids (400 mesh) were purchased from Electron Microscopy Sciences (Hatfield, PA, USA). Cell lines (mouse monocyte [macrophage] cells [J774A.1] and human breast adenocarcinoma cells [MCF-7]) were obtained from American Type Culture Collection (ATCC, Manassas, VA, USA).

\section{Synthesis of anionic-modified CNCs (CNCs-AMINE, CNCs-poly(NIPAAm), CNCs- $\beta$-CD)}

Both CNCs-AMINE and CNCs-poly(NIPAAm) were prepared previously in our laboratory and their syntheses and 


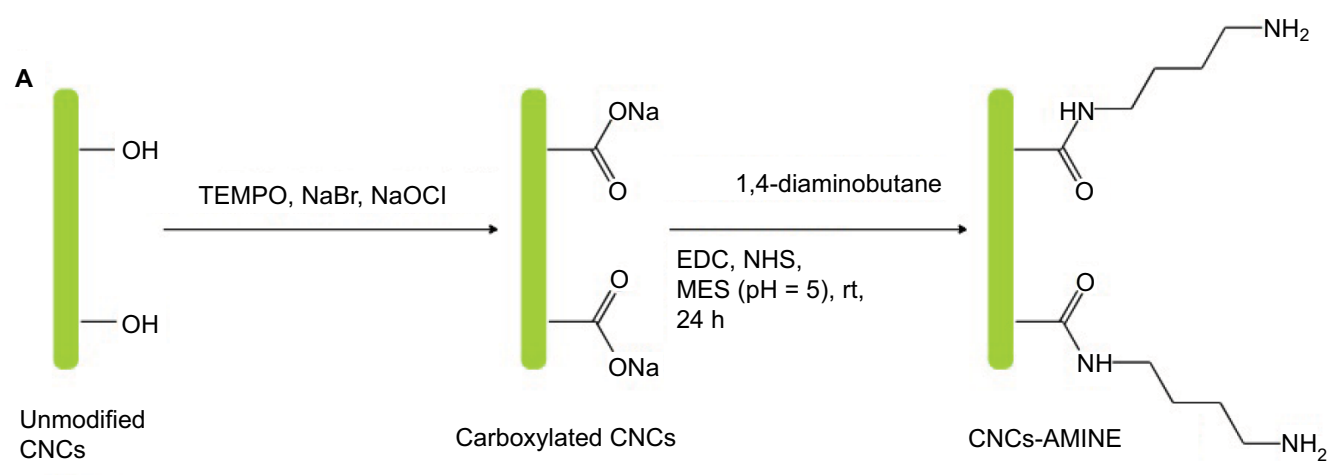

B

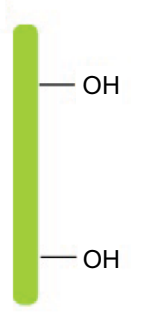

Unmodified CNCs

C

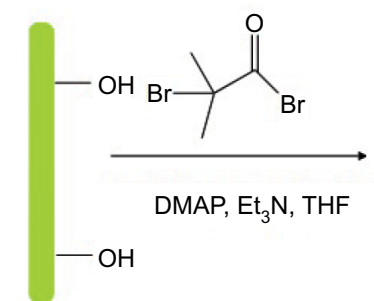

Unmodified CNCs
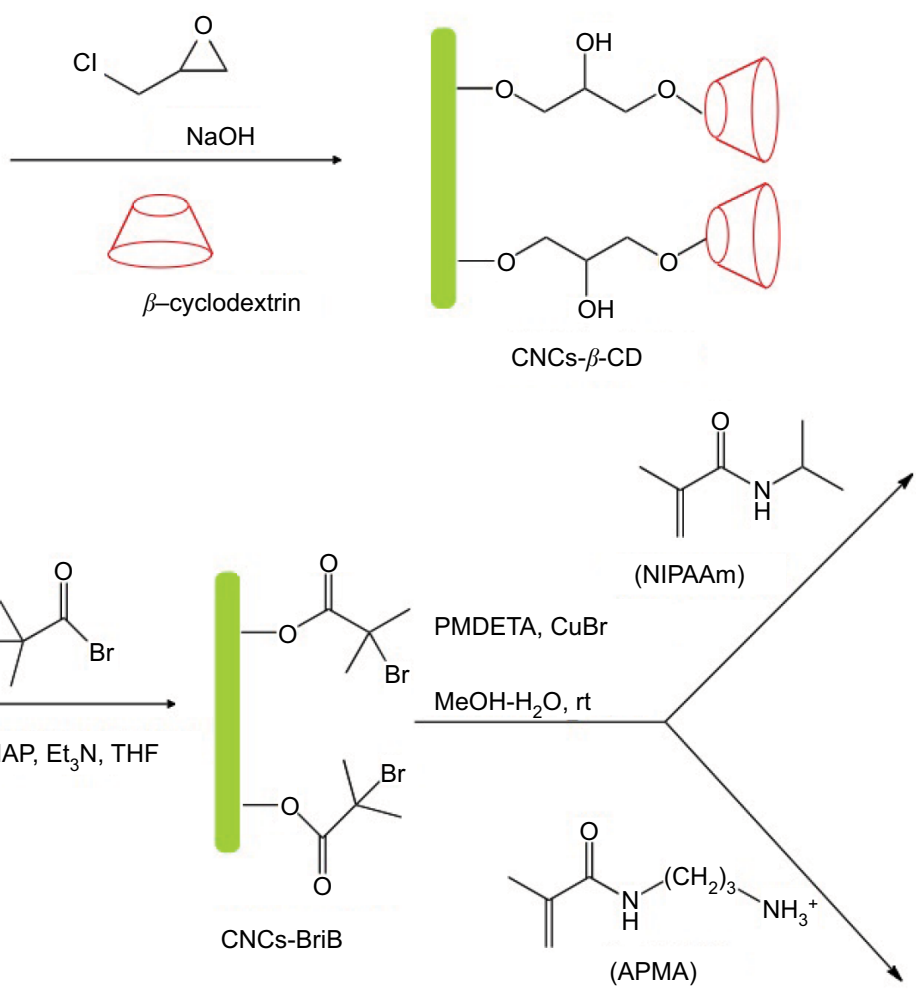<smiles>COCC(O)COCCC1C2CC3CC(C2)CC1C3</smiles><smiles>COC(=O)C(C)(C)C(C)(C)C(C)(C)C(=O)NC(C)CBr</smiles>

CNCs-poly(NIPAAm)<smiles>COC(=O)C(C)(C)C(C)(C)C(C)(C)C(=O)NCCN[SiH3]</smiles>

CNCs-poly(APMA)

Scheme I Synthesis of surface-modified CNCs (A) anionic CNCs-AMINE, (B) anionic CNCs- $\beta$-CD, (C) anionic CNCs-poly(NIPAAm) and cationic CNCs-poly(APMA). Abbreviations: AMINE, amino-functionalized; CNCs, cellulose nanocrystals; CNCs- $\beta$-CD, CNCs grafted with $\beta$-cyclodextrin; poly-(APMA), poly-( $N$-3-aminopropyl) methacrylamide; poly-(NIPAAm), poly(N-isopropylacrylamide); rt, room temperature; EDC, N-Ethyl-N'-(3-dimethylaminopropyl)carbodiimide; NHS, N-hydroxysuccinimide; MES, 2-(N-Morpholino)ethanesulfonic acid; THF, tetrahydrofuran; DMAP, 4-(Dimethyamino)pyridine; PMDETA, $N, N^{\prime} N^{\prime}, N^{\prime \prime}, N^{\prime \prime}$-pentamethyldiethylenetriamine.

characterization were fully described elsewhere. ${ }^{31,32} \mathrm{CNCs}$ grafted with $\beta$-cyclodextrin (CNCs- $\beta$-CD) was synthesized according to a previously reported one-step procedure using epichlorohydrin as a coupling reagent under alkaline conditions with slight modifications (Lin and Dufresne 2013). ${ }^{33}$ $\beta$-CD (10.35 g, $9.12 \mathrm{mmol})$ was added to an aqueous
$\mathrm{NaOH}$ solution $(4 \mathrm{~g} \mathrm{NaOH}$ in $20 \mathrm{~mL}$ of distilled water). A homogeneous suspension of CNCs $(1 \mathrm{~g}$ in $20 \mathrm{~mL}$ of distilled water) was then added in the $\beta$-CD alkaline solution, and the mixture was stirred for $30 \mathrm{~min}$. The desired amount of epichlorohydrin $(5.96 \mathrm{~mL}, 76 \mathrm{mmol})$ was added into the reaction mixture, and the reaction was heated at $40^{\circ} \mathrm{C}$ for $6 \mathrm{~h}$. The 
epichlorohydrin/cyclodextrin molar ratio was controlled at about 9 to avoid self-cross-linking of $\beta$-CD as suggested by Zhao et $\mathrm{al}^{34}$ and Lin and Dufresne ${ }^{33}$ The mixture was centrifuged at 12,000 rpm for $20 \mathrm{~min}$ and washed repeatedly with distilled water to ensure removal of both ungrafted $\beta$-CD and residual $\mathrm{NaOH}$. For high purity sample, the product was resuspended in water and dialyzed against deionized water for 1 week. The suspension was subsequently freeze-dried to afford a white powder (1.152 g). The grafting efficiency of $\beta$-CD on CNCs was evaluated using the method of weight measurement. Three grafting experiments were repeated for an average grafting efficiency of $15.1 \mathrm{wt} \%$, which was in close agreement with previously reported values. ${ }^{33}$

\section{Synthesis of cationic-modified CNCs Preparation of the cationic monomer,APMA hydrochloride}

APMA hydrochloride was synthesized using a mild and protecting group-free modified version of a previously reported procedure. ${ }^{35}$ 1,3-diaminopropane $(8 \mathrm{~mL}, 96 \mathrm{mmol})$ in $\mathrm{MeOH}$ $(50 \mathrm{~mL})$ was added to a stirred solution of 1,3-diaminopropane dihydrochloride (13.3 g, $90 \mathrm{mmol})$ in distilled water $(75 \mathrm{~mL})$ at $0^{\circ} \mathrm{C}$. After stirring the reaction mixture for $1 \mathrm{~h}$, methacrylic anhydride $(28 \mathrm{~mL}, 184 \mathrm{mmol})$ and a few crystals of hydroquinone in $\mathrm{MeOH}(50 \mathrm{~mL})$ were subsequently added dropwise. The reaction mixture was allowed to warm to room temperature and was stirred for $24 \mathrm{~h}$ in the dark, after which concentrated hydrochloric acid $(25 \mathrm{~mL})$ was added dropwise and stirring was maintained for another 2 h. Removal of solvent under vacuum, followed by washing with acetone produced the crude off-white residue, which upon recrystallization using hot 2-propanol gave rise to the desired APMA hydrochloride as a white solid in 52\% yield: ${ }^{1}$ H NMR (D $20,400 \mathrm{MHz}) \delta 1.78(\mathrm{~s}, 3 \mathrm{H}), 1.78-1.75(\mathrm{~m}, 2 \mathrm{H})$, $2.88(\mathrm{t}, J=7.5 \mathrm{~Hz}, 2 \mathrm{H}), 3.22(\mathrm{t}, J=6.8 \mathrm{~Hz}, 2 \mathrm{H}), 5.32(\mathrm{~s}, 1 \mathrm{H})$, $5.56(\mathrm{~s}, 1 \mathrm{H})$ (Figure $\mathrm{S} 1) ;{ }^{13} \mathrm{C}$ NMR $\left(\mathrm{D}_{2} \mathrm{O}, 100 \mathrm{MHz}\right) \delta 17.5$, 26.6, 36.1, 36.9, 121.2, 138.8, 172.2 ppm (Figure S2).

\section{Preparation of cationic CNCs- poly(APMA)}

The initiator modified-CNCs (CNCs-BriB) was prepared according to our previously reported procedure using a $5: 3$ ratio of 2-bromoisobutyryl bromide to anhydroglucose units (AGU) in $\mathrm{CNCs} .{ }^{36} \mathrm{CNCs}-\mathrm{BriB}$ was then grafted with the cationic monomer poly(APMA) via surface-initiated single-electron transfer living radical polymerization (SISET-LRP) technique at a ratio of monomer to AGU:(APMA/ $A G U)=50: 3$. The preparation of CNCs-poly(APMA) is as follows: CNCs-BriB (350 mg) was dispersed in a $\mathrm{H}_{2} \mathrm{O}: \mathrm{MeOH}$ solvent mixture $(100 \mathrm{~mL}, 1: 1)$ in a $250 \mathrm{~mL}$ Schlenk flask. After degassing the reaction mixture under $\mathrm{N}_{2}$ gas, APMA hydrochloride (8.94 g, $50 \mathrm{mmol}$ ) and copper (I) bromide (0.143 g, $1 \mathrm{mmol})$ were added. The suspension was degassed again before addition of PMDETA $(0.209 \mathrm{~mL}, 1 \mathrm{mmol})$ and reaction mixture was stirred for $24 \mathrm{~h}$ at room temperature. The resulting poly(APMA)-grafted CNCs was then centrifuged $\left(3 \times 12,000 \mathrm{rpm}\right.$ at $10^{\circ} \mathrm{C}$ for $\left.20 \mathrm{~min}\right)$ with 1:3 $\mathrm{H}_{2} \mathrm{O}: \mathrm{MeOH}$. The residual solid was resuspended in water and dialyzed against deionized water for 1 week with daily changes of deionized water. The suspension was then freeze-dried to afford a white flaky solid.

\section{Instrumentations}

\section{Fourier transform infrared spectroscopy (FT-IR)}

FT-IR spectra were acquired on a Varian FT-IR spectrophotometer (FTS-7000; Agilent Technologies, Santa Clara, CA, USA) using freeze-dried samples at room temperature under continuous nitrogen purging. Potassium bromide (previously dried in an oven at $150^{\circ} \mathrm{C}$ ) pellets were prepared by grinding and compressing about $2 \%$ of the CNCs samples in potassium bromide. Spectra in the range of $4000-400 \mathrm{~cm}^{-1}$ were obtained with a resolution of $4 \mathrm{~cm}^{-1}$ by cumulating 32 scans.

\section{Dynamic light scattering (DLS) and zeta potential measurements}

DLS and zeta potential measurements were carried out using a Malvern Zetasizer Nano-S instrument (Malvern Instruments Inc., Westborough, MA, USA). This instrument is equipped with a $4.0 \mathrm{~mW} \mathrm{He}-\mathrm{Ne} \operatorname{laser}(\lambda=633 \mathrm{~nm})$ and an avalanche photodiode detector and works at a $173^{\circ}$ scattering angle. Prior to the measurements, the CNCs suspensions $(0.1 \mathrm{wt} \%)$ were equilibrated at room temperature for $10 \mathrm{~min}$ in a temperature-regulated cell at $25.0 \pm 0.1^{\circ} \mathrm{C}$. Comparative effective hydrodynamic diameters and size distributions were obtained using DLS. The reported $\mathrm{d}_{h y d}$ (hydrodynamic size) is effective diameter based upon the intensity of scattered light. Both DLS and zeta $(\zeta)$ potential measurements were performed at neutral $\mathrm{pH}$. Triplicates were measured for each sample, and averages are reported.

\section{Scanning transmission electron microscopy (STEM)}

High resolution scanning electron microscopy (SEM) with a Hitachi model S-4800 or S-5500 apparatus equipped with 
a field emission source and operating at an accelerating voltage of $30 \mathrm{kV}$ in the transmission mode SEM was used to investigate the morphologies of the samples. The latter were prepared by depositing a drop of the filtered colloidal suspension on a TEM grid for $3 \mathrm{~min}$ and the excess liquid was wicked off using filter paper. After drying the TEM grid at room temperature for $3 \mathrm{~min}$, a drop of uranyl acetate solution ( $2 \mathrm{wt} \%$ in water) was deposited on the grid for 5 min for staining and the excess solution was removed using filter paper. Imaging was carried out on samples previously dried for at least $24 \mathrm{~h}$ at room temperature.

\section{Cell culture and cytotoxicity assays}

Cell culture

The culture of mouse monocyte (macrophage) cells (J774A.1; ATCC) was carried out in Roswell Park Memorial Institute 1640 medium supplemented with $10 \%$ fetal bovine serum (FBS), penicillin, streptomycin and L-glutamine. Human breast adenocarcinoma cells (MCF-7; ATCC) were cultured in DMEM medium, supplemented with $10 \% \mathrm{FBS}$, essential amino acids $(0.1 \mathrm{mM})$, insulin $(10 \mathrm{ug} / \mathrm{mL})$, sodium pyruvate ( $1 \mathrm{mM})$, penicillin, streptomycin and L-glutamine. Both cell lines were incubated at $37^{\circ} \mathrm{C}$ in a $5 \% \mathrm{CO}_{2}$-supplemented atmosphere for at least $24 \mathrm{~h}$ before the appropriate treatments.

\section{3-(4,5-dimethylthiazol-2-yl)-2,5-} diphenyltetrazolium bromide (MTT) assay The cytotoxicity of the unmodified CNCs and its derivatives was assessed by a MTT assay. J774A.1 and MCF-7 cells were seeded in 96-well plates at a density of $5 \times 10^{5}$ cells/ $\mathrm{mL}$. After $24 \mathrm{~h}$, they were treated with unmodified CNCs and its derivatives at $10,25,50$ and $100 \mu \mathrm{g} / \mathrm{mL}$, for $24 \mathrm{~h}$ or $48 \mathrm{~h}$. After suspending all the compounds in sterile PBS, the medium was removed and the wells were filled with fresh culture medium with $0.5 \mathrm{mg} / \mathrm{mL} \mathrm{MTT}$. After $30 \mathrm{~min}$ for J774A. 1 and 45 min for MCF-7, the medium was removed and the insoluble crystals were solubilized with $200 \mu \mathrm{L} /$ well of dimethyl sulfoxide. The absorbance was measured at 570 nm using a Synergy H1 Hybrid Multi-Mode Microplate Reader (BioTek, Winoski, VT, USA).

\section{Lactate dehydrogenase (LDH) assay}

Unmodified and modified CNCs were suspended as described in MTT assay, and J774A.1 and MCF-7 cells were also seeded and treated as in MTT assay. The maximum LDH activity was obtained with cells treated with triton $1 \%$ for $30 \mathrm{~min}$. The spontaneous control activity was obtained from untreated cells. LDH-released activity in all conditions was assessed in the cell-free supernatants (medium) according to the manufacturer's instruction (Promega, Madison, WI, USA), spectrophotometrically at $490 \mathrm{~nm}$ in a Synergy H1 Hybrid Multi-Mode Microplate Reader (BioTek). The percentage of cytotoxicity was calculated according to the following formula,

$\%$ Cytotoxicity $=\underline{\text { Compound-treated LDH activity }- \text { Spontaneous LDH activity } \times 100}$ Maximum LDH activity - Spontaneous LDH activity

\section{Statistical analysis}

Data were analyzed by 2-way analysis of variance and post hoc Dunnett's multiple comparison test (GraphPad Prism, La Jolla, CA, USA), and significant differences were considered at $p<0.01$.

\section{Results and discussion Synthesis and characterization of anionic- and cationic-modified $\mathrm{CNCs}$}

Amino-functionalized CNCs (CNCs-AMINE) was prepared using simple covalent chemistry via a mild 2-step synthetic approach. The primary alcohol of CNCs was first oxidized via (2,2,6,6-tetramethylpiperidin-1-yl)oxidanyl-mediated oxidation to the corresponding carboxylated CNCs. Subsequently, amidation (1-ethyl-3-(3-dimethylaminopropyl)carbodiimide/ $N$-hydroxysuccinimide-mediated coupling) with 1,4-diaminobutane afforded the desired CNCs-AMINE (Scheme 1). The chemical and morphological features of CNCs-AMINE were extensively analyzed using a combination of analytical, spectroscopic, and microscopic techniques as previously described. ${ }^{31}$ The presence of the amino group on the surface of $\mathrm{CNCs}$ represents a versatile reactive functional group for a number of bioconjugation strategies as required for bio-applications.

Cyclodextrins (CD), a series of cyclic oligosaccharides, have emerged as attractive building blocks for pharmaceutical and biomedical applications due to their inherent ability to host biologically active molecules and protect them from the external environment. ${ }^{37}$ As such, CNCs surfaces were covalently ${ }^{33}$ and non-covalently ${ }^{38}$ modified with CD for the design of drug delivery carriers. However, the lack of current cytotoxicity data of CNCs grafted with $\beta$-CD further motivated us to synthesize this material following the reported procedure of Lin and Dufresne. ${ }^{33} \mathrm{CNCs}-\beta-\mathrm{CD}$ was obtained by reaction of unmodified CNCs with $\beta$-CD in the presence of epichlorohydrin as coupling agent under alkaline condition (Scheme 1). The success of the covalent grafting reaction was confirmed by FT-IR spectroscopy with 
decrease in peak intensities located at 1163, 1113, and 1059 $\mathrm{cm}^{-1}$ as well as peak broadening at $1031 \mathrm{~cm}^{-1}$ (C-O stretching band) (Figure $1 \mathrm{C}$ and S3 for peak expansion). ${ }^{33}$ An average grafting efficiency of $15.1 \mathrm{wt} \%$ of $\beta$-CD covalently grafted on the surface of CNCs was obtained based on the method of weight measurement. Both FT-IR and grafting efficiency results were in good agreement with previously reported values. ${ }^{33}$ While the above 2 synthetic routes for preparation of anionic-modified CNCs (CNCs-AMINE and CNCs- $\beta$-CD) involved simple conjugation chemistries, we further included in our study an anionic and a cationic surface-modified CNCs possessing different polymeric architectures using living radical polymerization technique. CNCs modified with polymeric structures will be useful in further assessing the effect of different surface chemistries on the cytotoxicity of modified CNCs. Polymer grafting on the surface of CNCs can impart its desired properties to CNCs for the development of "smart" materials for biomedical applications. CNCs grafted with poly( $N$-isopropylacrylamide) (CNCs-poly(NIPAAm)) was prepared and characterized as previously described in our laboratory using the SI-SET-LRP technique (Scheme 1). ${ }^{32}$ Poly(NIPAAm) is the polymer of choice in this study given its thermoresponsive nature as well as its wide applications in drug delivery and tissue engineering. ${ }^{39}$ SET-LRP is an emerging robust and versatile polymerization method for designing functional materials with complex molecular architectures in a facile manner. ${ }^{40}$ Cationic APMA has been previously employed as functional component in the design of drug delivery carriers ${ }^{41,42}$ and thus, makes it an attractive polymeric material to be coated on the surface of CNCs as well as evaluating its potential cytotoxicity. Using the same SI-SET-LRP approach, the novel CNCs-poly(APMA) was prepared and characterized for its chemical and morphological features using a combination of spectroscopic, microscopic and analytical techniques. When compared with unmodified CNCs (Figure 1A), FT-IR analysis of the purified CNCs-poly(APMA) displayed new FT-IR peaks typical for the amide stretch $\left(1638 \mathrm{~cm}^{-1}\right)$ and amine bend $\left(1538 \mathrm{~cm}^{-1}\right)$ (Figure 1B). ${ }^{36}$ Upon polymerization, the anionic surface of unmodified CNCs turned cationic as evidenced by zeta potential measurements (Table 1). Elemental analysis of CNCs-poly(APMA) indicated an increase in the carbon content and presence of nitrogen that further supported the successful grafting of polymer brushes from the surface of CNCs (Table S1).

Table I DLS and $\zeta$-potentials for anionic and cationic surfacemodified CNCs

\begin{tabular}{lll}
\hline Sample & $\begin{array}{l}\text { Hydrodynamic } \\
\text { diameter }(\mathbf{n m})\end{array}$ & $\zeta$-potentials $(\mathbf{m V})$ \\
\hline Unmodified CNCs & $87.2 \pm 1.2$ & $-58.2 \pm 0.5$ \\
CNCs-AMINE & $125.4 \pm 0.2$ & $-26.0 \pm 2.0$ \\
CNCs- $\beta$-CD & $131.3 \pm 0.3$ & $-28.1 \pm 1.5$ \\
CNCs-poly(NIPAAm) & $126.9 \pm 0.4$ & $-22.4 \pm 1.5$ \\
CNCs-poly(APMA) & $154.6 \pm 3.6$ & $+45.2 \pm 1.3$ \\
\hline
\end{tabular}

Note: Data presented as mean $\pm S D$.

Abbreviations: AMINE, amino-functionalized; CNC, cellulose nanocrystals; CNCs$\beta$-CD, CNCs grafted with $\beta$-cyclodextrin poly(APMA), poly(N-3-aminopropyl) methacrylamide; poly(NIPAAm), poly(N-isopropylacrylamide);DLS,Dynamic light scattering.

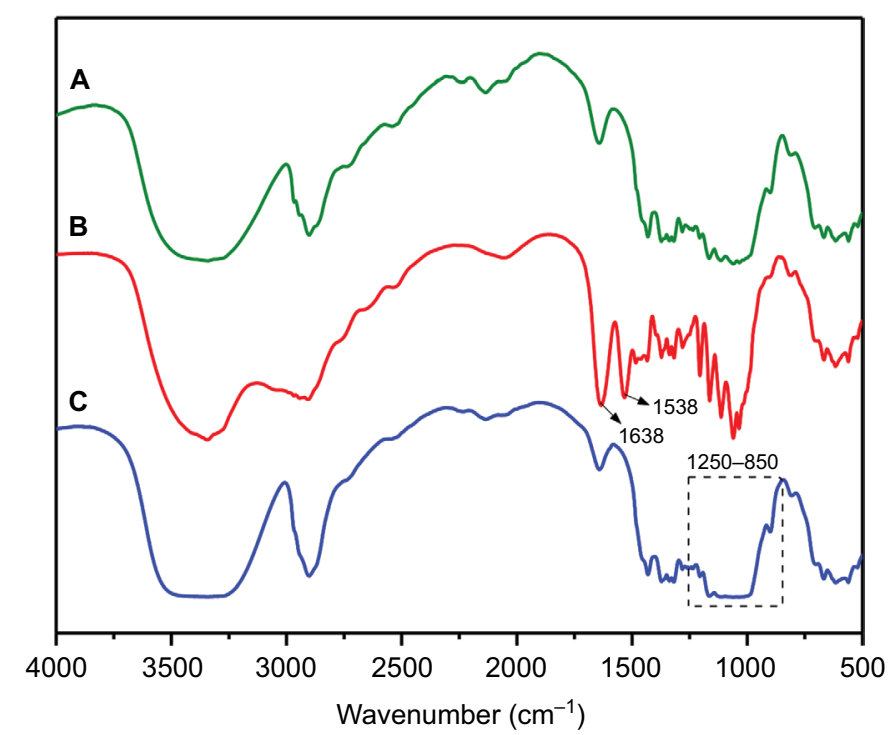

Figure I FT-IR of (A) unmodified CNCs, (B) CNCs-poly(APMA), (C) CNCs- $\beta$-CD.

Abbreviations: CNCs, cellulose nanocrystals; $C N C s-\beta-C D, C N C s$ grafted with $\beta$-cyclodextrin; FT-IR, Fourier transform infrared spectroscopy; poly(APMA), poly( $N$-3aminopropyl)methacrylamide; poly(NIPAAm), poly( $N$-isopropylacrylamide). 


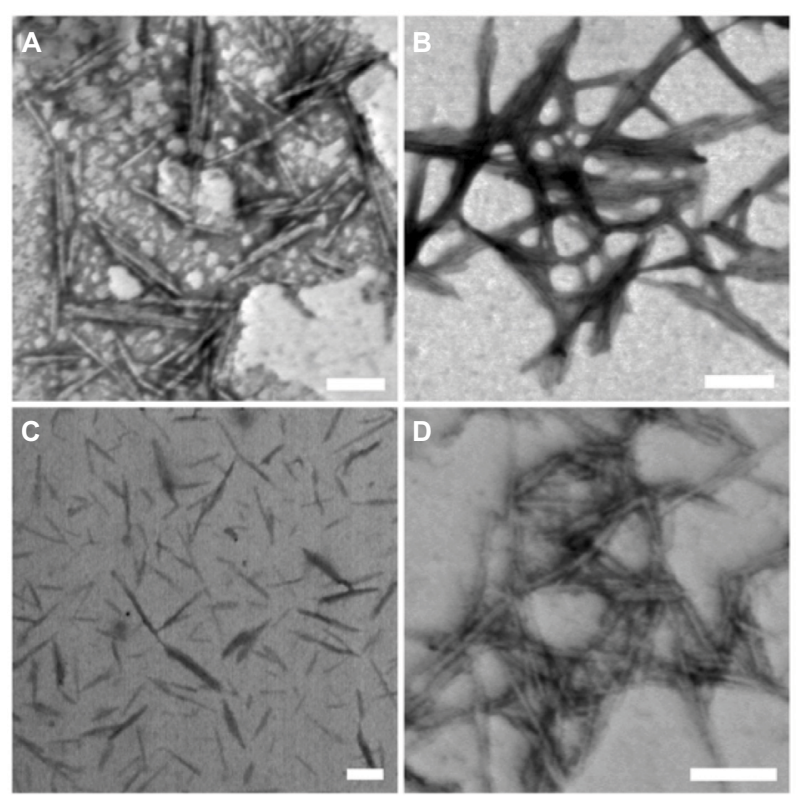

Figure 2 STEM images of unmodified and modified CNCs: (A) unmodified CNCs, (B) CNCs-AMINE, (C) CNCs-poly(NIPAAm), and (D) CNCs-poly(APMA). Note: Scale bar $=100 \mathrm{~nm}$.

Abbreviations: AMINE, amino-functionalized; CNCs, cellulose nanocrystals; CNCs- $\beta$-CD, CNCs grafted with $\beta$-cyclodextrin; poly(APMA), poly(N-3aminopropyl)methacrylamide; poly(NIPAAm), poly( $N$-isopropylacrylamide); STEM, scanning transmission electron microscopy.

STEM was used to visualize the morphologies of the unmodified and modified CNCs (Figure 2). The STEM images of the unmodified and modified CNCs showed welldispersed rod-like nanoparticles with size around 100-300 $\mathrm{nm}$ in length and $10-20 \mathrm{~nm}$ in diameter. In addition to STEM analyses, DLS was used to obtain comparative apparent particle sizes of the modified CNCs as depicted in Table 1. However, it is important to note that DLS is routinely used to measure hydrodynamic size of spherical particles and thus, the obtained results do not represent the actual dimensions.

Given the importance of highly purified materials for the correct interpretation of biological results, all the synthesized modified CNCs were extensively purified by repeated centrifugation and dialysis to ensure efficient removal of unreacted reagents, monomers, and homopolymers prior to all analyses.

\section{Cell viability analysis of surface-modified CNCs}

The potential applicability of cellulose-based nanomaterials for biomedical purposes is rapidly emerging, therefore, it is crucial that cytotoxicity studies of modified CNCs are performed in parallel with characterization of these newly synthesized nanomaterials. The cytotoxicity of unmodified and modified CNCs was assessed using both MTT and LDH assays on 2 different cell lines, J774A.1 and MCF-7. The cytotoxicity assay using MTT is based on the conversion of MTT into formazan crystals by living cells, indicating mitochondrial activity that can be associated with percentage of viable cells. ${ }^{43}$ Results from the MTT assay in J774A. 1 cells with $24 \mathrm{~h}$ of treatment showed that CNCspoly(NIPAAm) was the only modified CNCs to significantly decrease cell viability at the intermediate dose $(50 \mu \mathrm{g} / \mathrm{mL})$. At the highest concentration $(100 \mu \mathrm{g} / \mathrm{mL})$, CNCs-AMINE and CNCs-poly(APMA) also had a significantly decreased cell viability similar to previously observed with CNCs$\operatorname{poly}(N$-[2-aminoethylmethacrylamide] $) .{ }^{36} \mathrm{CNCs}-\beta-\mathrm{CD}$, as well as unmodified CNCs, did not affect cell viability
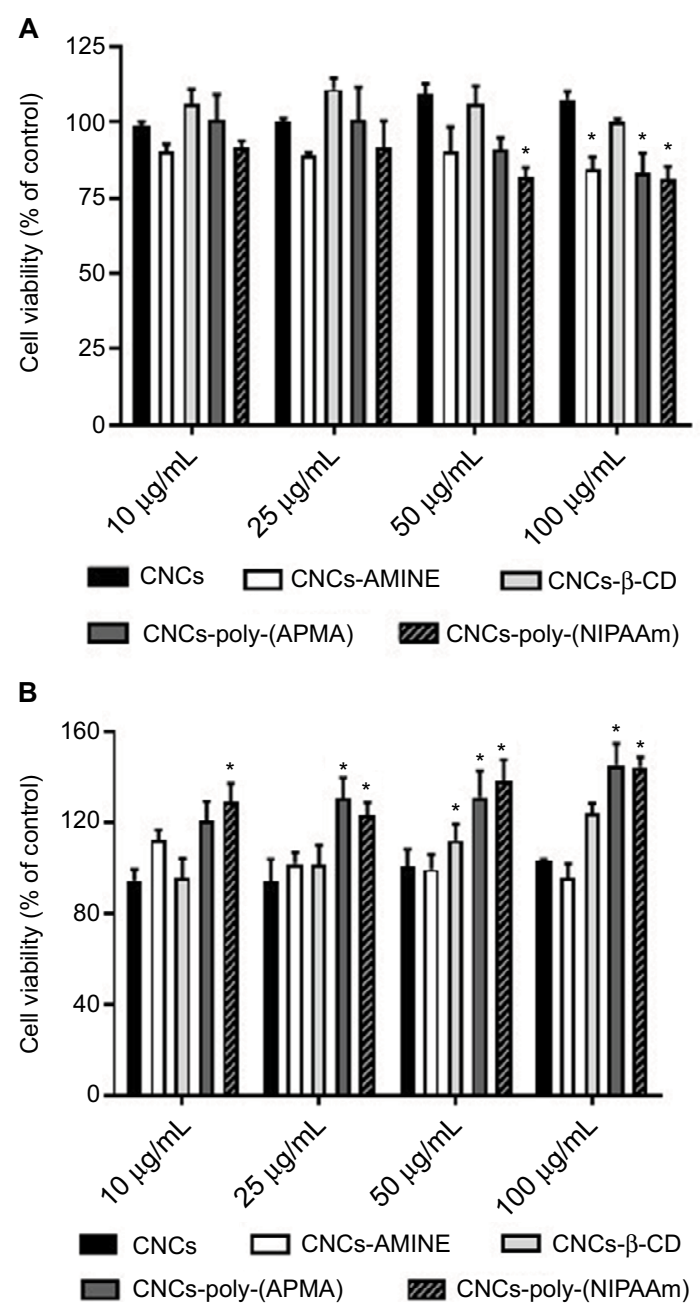

Figure 3 Cytotoxicity of unmodified and modified CNCs on J774A.I (A) and MCF7 (B) cells.

Notes: After $24 \mathrm{~h}$ of treatment, cell viability was determined by MTT assay. Data are expressed as percentage of control (non-treated cells, 100\% viability) using the mean value and SD from triplicate experiments. ${ }^{*} p<0.01$ compared to control.

Abbreviations: AMINE, amino-functionalized; $\mathrm{CNCs}$, cellulose nanocrystals; CNCs- $\beta$-CD, CNCs grafted with $\beta$-cyclodextrin; MTT, 4,5-dimethylthiazol-2-yl-2,5diphenyltetrazolium bromide; poly(APMA), poly( $N$-3-aminopropyl)methacrylamide; poly(NIPAAm), poly(N-isopropylacrylamide). 
under these tested conditions (Figure 3A). In MCF-7 cells, CNCs-AMINE and CNCs- $\beta$-CD did not affect cell viability nor increased the conversion of MTT into formazan with 24 $\mathrm{h}$ of treatment. However, CNCs-poly(NIPAAm) increased the conversion of MTT into formazan, even at the lowest concentration (Figure 3B). A similar effect was also observed with $\mathrm{CNCs}$ grafted with poly( $N$-[2-aminoethylmethacrylamide]). ${ }^{36}$ Some studies have indicated that the quantity of formazan crystals produced is not solely dependent on cell number. ${ }^{44,45}$ The MTT assay is based on the conversion of the tetrazolium dye to formazan mainly by mitochondrial succinic dehydrogenases. However, cytosolic enzymes such as nicotinamide adenine dinucleotide (NADH) reductase and flavin oxidase may also play a role in this conversion. ${ }^{46}$ In addition, the rate of conversion to formazan has been shown to be linked to the cellular metabolic activity as well as the number of mitochondria present in the cell. Therefore, larger cells with more mitochondria have a higher rate of tetrazolium conversion. ${ }^{47}$ As such, this apparent increase in percentage of viable cells seen in MCF-7 cells might be explained by a potential effect in increases on mitochondrial activity, which is not necessarily associated with increases in cell viability and proliferation.

We also performed LDH activity assay, which indirectly assessed membrane permeability. LDH is a cytosolic enzyme present in many different types of cells and its release to cell medium can be used as an indication of plasma membrane damage. The released LDH can be quantified in the medium by a coupled enzymatic reaction. Initially, LDH catalyzes the conversion of lactate to pyruvate via reduction of NAD + to NADH. Subsequently, diaphorase uses NADH to reduce a tetrazolium salt (INT) to a red formazan product. Therefore, the level of formazan formation is directly proportional to the amount of released LDH in the medium, which is related to membrane damage. ${ }^{48,49}$ The $24 \mathrm{~h}$ exposure data did not demonstrate any significant differences on the LDH activity between medium from control (untreated cells) and from cells treated with unmodified and modified CNCs, in both cell lines (data not shown). Next, we decided to verify whether these cellulose-based nanomaterials somehow developed cytotoxicity over time, by increasing the incubation time to $48 \mathrm{~h}$, in both cell lines. Again, depending on cell type, the modified CNCs displayed substantial differences on the level of toxicity. Data from MTT assay showed that cell viability of J774A.1 was slightly diminished, but statistically significant in almost all concentrations of CNCs tested, including unmodified CNCs (Figure 4A). Interestingly, in MCF-7 cell line, CNCs-AMINE was the only modified
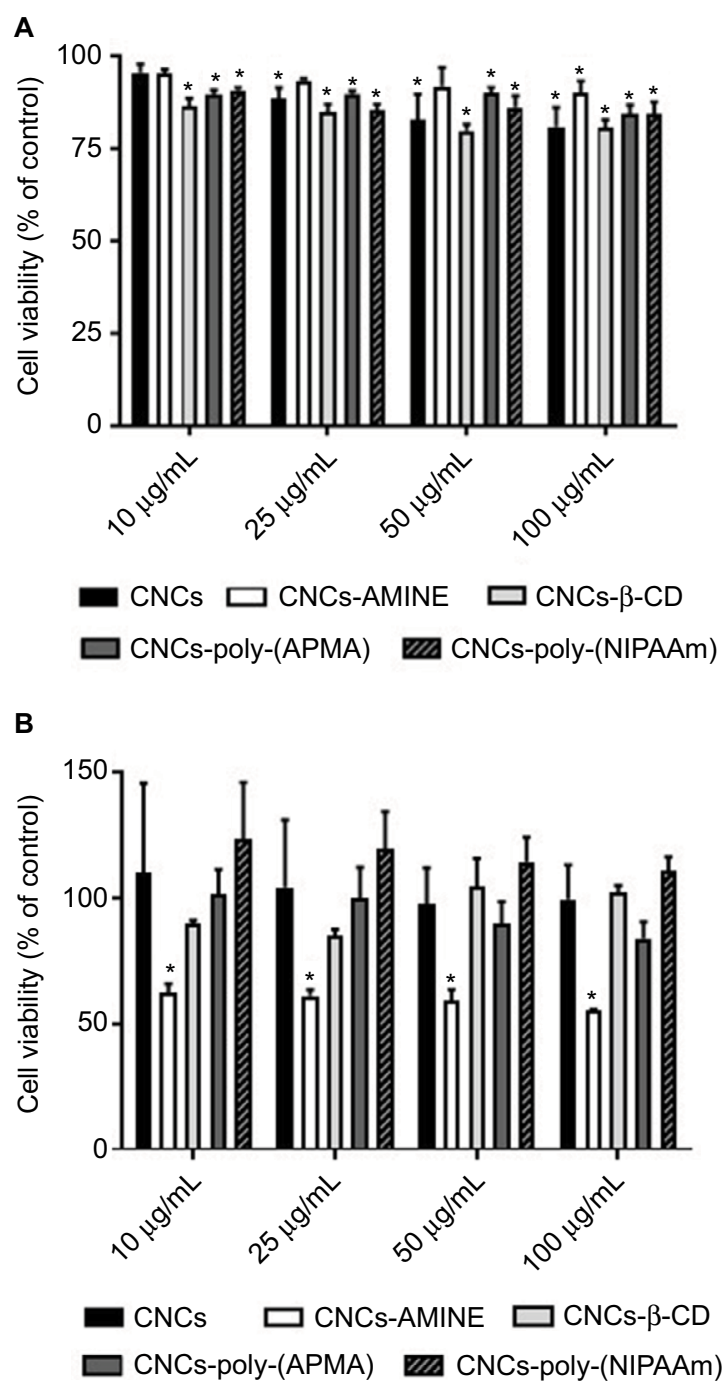

Figure 4 Cytotoxicity of unmodified and modified CNCs on J774A.I (A) and MCF7 (B) cells.

Notes: After $48 \mathrm{~h}$ of treatment, cell viability was determined by MTT assay. Data are expressed as percentage of control (non-treated cells, $100 \%$ viability) using the mean value and SD from triplicate experiments. ${ }^{*} p<0.01$ compared to control.

Abbreviations: AMINE, amino-functionalized; CNCs, cellulose nanocrystals; CNCs- $\beta$-CD, CNCs grafted with $\beta$-cyclodextrin; MTT, 4,5-dimethylthiazol2-yl-2,5-diphenyltetrazolium bromide; poly-(APMA), poly-( $N$-3-aminopropyl) methacrylamide; poly-(NIPAAm), poly( $N$-isopropylacrylamide).

CNCs that showed a significant degree of cytotoxicity at all concentrations, but not in a dose-dependent manner. Since this effect is only observed with MTT assay and not with LDH assay, it implies that it is not related to membrane damage. The effect on increased conversion of MTT into formazan in MCF-7 cells is no longer observed for all the CNCs (Figure 4B).

Upon $48 \mathrm{~h}$ of incubation with unmodified and modified CNCs, the level of LDH activity detected in the medium of MCF-7 cells was no different among groups (data not shown). However, in the medium of J774A.1 cells, we observed significant differences in LDH activity between control (non- 
treated cells) and the modified CNCs-treated groups. With a longer incubation time, CNCs-poly(NIPAAm) exhibited the least increases in the membrane permeability of the cells, since only at $100 \mu \mathrm{g} / \mathrm{mL}$ LDH activity was significantly detected in the medium. The other modified CNCs, however, started to show effects on membrane permeability with concentration as low as $10 \mu \mathrm{g} / \mathrm{mL}$. Surprisingly, CNC- $\beta$-CD showed the strongest effect on the increases in LDH activity at all concentrations tested (Figure 5).

$\mathrm{CD}$ are complex cyclic oligosaccharides with a hydrophobic cavity. As a consequence, they are widely used by the pharmaceutical industry as drug carriers to increase water solubility of numerous hydrophobic molecules. ${ }^{50}$ However, the hydrophobicity of $\mathrm{CD}$ can also cause this polymer to interact with lipophilic macromolecules, such as cholesterol and fatty acids in the biological milieu. In fact, the majority of research involving $\mathrm{CD}$ has focused on their ability to manipulate lipid (phospholipids and cholesterol) composition in different cells because these lipophilic macromolecules can be easily entrapped inside the cavity of CD. ${ }^{51}$ Thus, a potential explanation for CNCs- $\beta$-CD to have the greatest effect on the increase of the LDH activity in the cell culture medium may be due to its ability to interact with lipids in the cell membrane therefore affecting membrane permeability. Although some modified CNCs caused a mild decrease in J774A. 1 cell viability at $24 \mathrm{~h}$ of treatment, the bright field microscopy images revealed that none of the modified CNCs

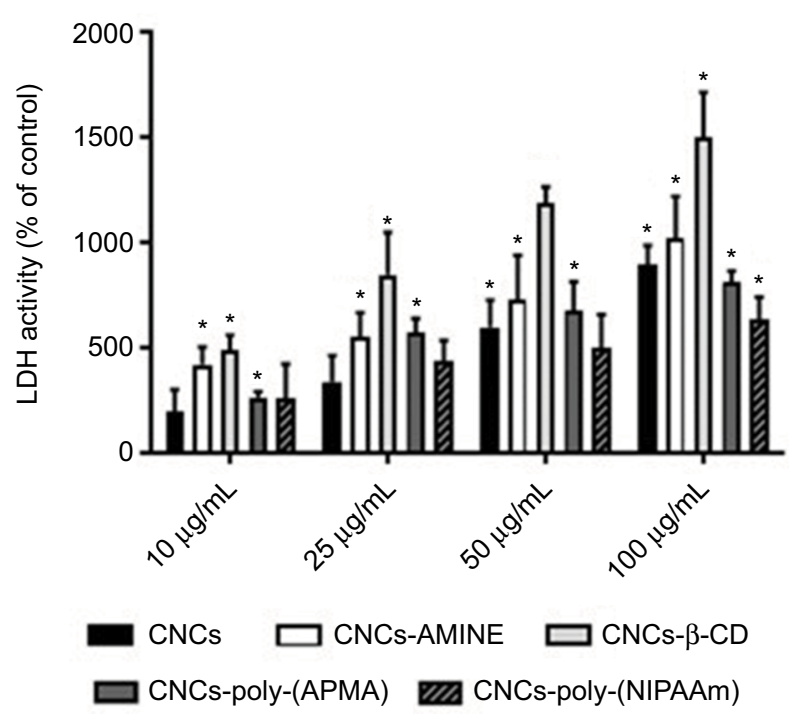

Figure 5 Cytotoxicity of unmodified and modified CNCs on J774A.I cells. Notes: After $48 \mathrm{~h}$ of treatment, cell viability was determined by LDH assay. Data are expressed as percentage of cytotoxicity over the control using the mean value and SD from triplicate experiments. ${ }^{*} p<0.01$ compared to control.

Abbreviations: $\mathrm{CNCs}$, cellulose nanocrystals; CNCs- $\beta-\mathrm{CD}$, CNCs grafted with $\beta$-cyclodextrin; LDH, lactate dehydrogenase; poly-(APMA), poly-(N-3-aminopropyl) methacrylamide; poly-(NIPAAm), poly(N-isopropylacrylamide).

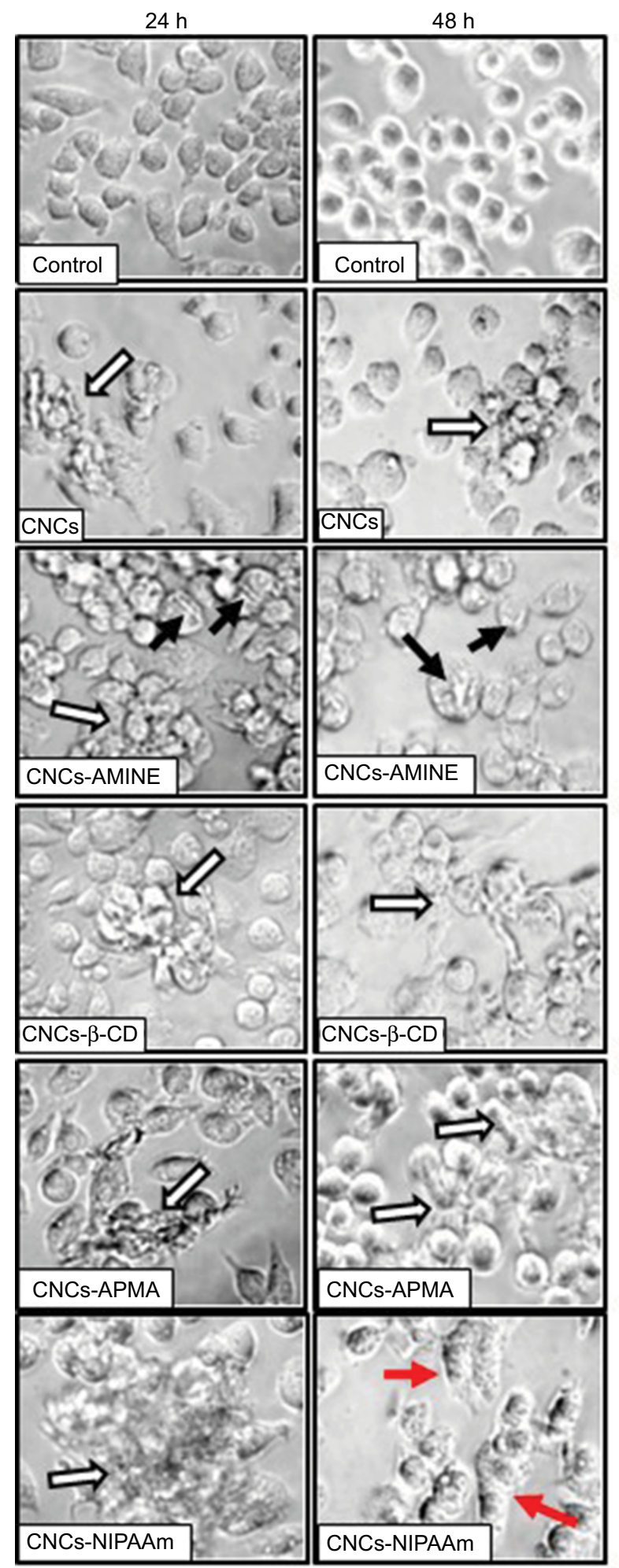

Figure 6 Microscope images of J774A.I cells treated with unmodified and modified CNCs $(50 \mu g / \mathrm{mL})$.

Notes: After indicated times of treatment, images of live cells were taken in bright field with inverted microscope at $400 \times$ magnification. White arrows indicate nanomaterial-cell aggregates, black arrows indicate membrane-nanomaterial interactions and red arrows indicate cell enlargement and elongation.

Abbreviations: AMINE, amino-functionalized; CNCs, cellulose nanocrystals; $\mathrm{CNCs}-\beta$-CD, CNCs grafted with $\beta$-cyclodextrin; APMA, (N-3-aminopropyl) methacrylamide; NIPAAm, $N$-isopropylacrylamide. 
$(50 \mu \mathrm{g} / \mathrm{mL})$ caused major changes in cell morphology, despite all of them interacting with the cells by mainly forming a "cluster" of cells surrounding the nanomaterial (Figure 6, first column, white arrows). Interestingly, CNCs-AMINE did not only evoke this "cell cluster" effect, but also showed that the small needle-like particles were spread over the cells (Figure 6, first column, third panel, black arrows). At 48 h, however, we observed some changes in cell morphology with most of the treatments. At this time point, treatment with CNCs-AMINE caused the cells to be enlarged and the images suggested that the small needle-like particles were interacting with the cell membrane most likely by penetrating into the cells (Figure 6, second column, third panel, black arrows). Interestingly, this modified CNCs was the only one that did not decrease J774A.1 cell viability at $50 \mu \mathrm{g} /$ $\mathrm{mL}$ dose, as shown with the MTT assay ([Figure 4A], white bars). CNCs-poly(NIPAAm) induced the most prominent change in the morphology of the J774A. 1 cells after $48 \mathrm{~h}$ of treatment, as observed by enlargement and elongation of the cells (Figure 6, second column, bottom panel, red arrows).

Overall, our results indicate that "cell clustering" effect and changes in cell morphology are cellular phenomena not necessarily directly related to decreases in cell viability. We do not exclude the possibility that these modifications will not lead to cell toxicity with more prolonged treatment with these nanomaterials. However, an early study with different preparations of carbon nanotubes (CNTs) showed that after long exposure (3 days of treatment), suspended CNT-bundles were less cytotoxic than CNT-agglomerates or asbestos in mesothelial cell morphology (MSTO-211H). The cytotoxicity apparently correlated with changes in cell morphology caused by CNT-agglomerates and asbestos, but not with CNTbundles. The authors conclude that the CNT-agglomerates are bigger, stiffer and more solid (similar to asbestos) than the CNT-bundles and these structural differences of the CNTs are the reason for cytotoxic response of the cells compared with asbestos. ${ }^{52}$ Overall, our results indicated that there is no direct correlation with decreases in cell viability and increases in cell permeability with $\zeta$-potential or relative size (sphereequivalent hydrodynamic diameter) of our surface-modified CNCs. This observation is consistent with the previously published work where neither the size nor the surface charge of the $\mathrm{ZnO}$ nanoparticles affected their cytotoxicity against U373MG cells. ${ }^{53}$ However, we do not exclude the possibility that the short length of CNCs derivative may contribute to less nanomaterial agglomeration or cell clustering formation around the $\mathrm{CNCs}$ and therefore better distribution onto the cell surface, resulting in less cytotoxicity.

\section{Conclusion}

This study examined the impact of surface organic coatings of CNCs on mammalian cell viability. Four different organic functional moieties ranging from simple organic molecules to complex polymeric structures were covalently conjugated on the surface of CNCs using different synthetic strategies. The in vitro toxicity of the modified CNCs using MTT and LDH assays was assessed on 2 different cell lines, J774A.1 and MCF-7, and unmodified and modified CNCs displayed marginal, but statistically significant decreases in cell viability depending on cell type and the period of incubation. Overall, the results indicated that cells exposed to surfacecoated CNCs for $24 \mathrm{~h}$ did not show major changes in cell viability, membrane permeability as well as cell morphology. However, at longer exposures, this scenario changed and more in-depth toxicological studies are needed to fully evaluate the biological interactions and safety of these surface-modified CNCs in humans and other mammals, as well as evaluation of immunogenicity, since some of the effects on biological systems are not directly related to cytotoxicity.

\section{Acknowledgments}

The authors thank SUNY Plattsburgh for a SUNY Presidential Research Award 2016-2017, the University of Alberta and the National Institute for Nanotechnology and National Research Council of Canada for supporting this project.

\section{Disclosure}

The authors report no conflicts of interest in this work.

\section{References}

1. Klemm D, Kramer F, Moritz S, et al. Nanocelluloses: a new family of nature-based materials. Angew Chem Int Ed Engl. 2011;50(24): 5438-5466.

2. Moon RJ, Martini A, Nairn J, Simonsen J, Youngblood J. Cellulose nanomaterials review: structure, properties and nanocomposites. Chem Soc Rev. 2011;40(7):3941-3994.

3. Habibi Y, Lucia LA, Rojas OJ. Cellulose nanocrystals: chemistry, selfassembly, and applications. Chem Rev. 2010;110(6):3479-3500.

4. Eichhorn SJ. Cellulose nanowhiskers: promising materials for advanced applications. Soft Matter. 2011;7(2):303-315.

5. Peng BL, Dhar N, Liu HL, Tam KC. Chemistry and applications of nanocrystalline cellulose and its derivatives: a nanotechnology perspective. Can J Chem Eng. 2011;89(5):1191-1206.

6. Lin N, Dufresne A. Nanocellulose in biomedicine: current status and future prospect. Eur Polym J. 2014;59:302-325.

7. Jorfi M, Foster EJ. Recent advances in nanocellulose for biomedical applications. J Appl Polym Sci. 2015;132(14):1097-4628.

8. Shvedova AA, Yanamala N, Kisin ER, et al. Long-term effects of carbon containing engineered nanomaterials and asbestos in the lung: One year post-exposure comparisons. Am J Physiol Lung Cell Mol Physiol. 2014;306(2):L170-L182.

9. Sunasee R, Hemraz UD, Ckless K. Cellulose nanocrystals: a verstatile nanoplatform for emerging biomedical applications. Expert Opin Drug Deliv. 2016;13(9):1243-1256. 
10. Roman M. Toxicity of cellulose nanocrystals: a review. Ind Biotechnol. 2015 11(1):25-33.

11. Shatkin JA, Kim B. Cellulose nanomaterials: life cycle risk assessment, and environmental health and safety roadmap. Environ Sci Nano. 2015;2(5):477-499.

12. Camarero-Espinosa S, Endes C, Mueller S, et al. Elucidating the potential biological impact of cellulose nanocrystals. Fibers. 2016;4(3):21.

13. Roman M, Dong S, Hirani A, Lee YW. Cellulose nanocrystals for drug delivery. In: Edgar KJ, Heinze T, Buchanan CM, editors. Polysaccharide Materials: Performance by Design. Washington, DC: American Chemical Society; 2009; 81-91.

14. Kovacs T, Naish V, O’Connor B, et al. An ecotoxicological characterization of nanocrystalline cellulose (NCC). Nanotoxicology. 2010;4(3):255-270.

15. Mahmoud KA, Mena JA, Male KB, Hrapovic S, Kamen A, Luong JH. Effect of surface charge on the cellular uptake and cytotoxicity of fluorescent labeled cellulose nanocrystals. ACS Appl Mater Interfaces. 2010;2(10):2924-2932.

16. Villanova JC, Ayres E, Carvalho SM, Patricio PS, Pereira FV, Oréfice RL. Pharmaceutical acrylic beads obtained by suspension polymerization containing cellulose nanowhiskers as excipient for drug delivery. Eur J Pharm Sci. 2011;42(4):406-415.

17. Jackson JK, Letchford K, Wasserman BZ, Ye L, Hamad WY, Burt HM. The use of nanocrystalline cellulose for the binding and controlled release of drugs. Int J Nanomedicine. 2011;6:321-330.

18. Clift MJ, Foster EJ, Vanhecke D, et al. Investigating the interaction of cellulose nanofibers derived from cotton with a sophisticated 3D human lung cell coculture. Biomacromolecules. 2011;12(10):3666-3673.

19. Male KB, Leung AC, Montes J, Kamen A, Luong JH. Probing inhibitory effects of nanocrystalline cellulose: inhibition versus surface charge. Nanoscale. 2012;4(4):1373-1379.

20. Ni H, Zeng S, Wu J, et al. Cellulose nanowhiskers: preparation, characterization and cytotoxicity evaluation. Biomed Mater Eng. 2012;22(1-3):121-127.

21. Dong S, Hirani AA, Colacino KR, Lee, YW, Roman M. Cytotoxicity and cellular uptake of cellulose nanocrystals. Nano Life. 2012;2(3):1241006.

22. Yang X, Bakaic E, Hoare T, Cranston ED. Injectable polysaccharide hydrogels reinforced with cellulose nanocrystals: Morphology, rheology, degradation, and cytotoxicity. Biomacromolecules. 2013;14(12):4447-4455.

23. Pereira MM, Raposo NR, Brayner R, et al. Cytotoxicity and expression of genes involved in the cellular stress response and apoptosis in mammalian fibroblast exposed to cotton cellulose nanofibers. Nanotechnology. 2013;24(7):075103.

24. Zoppe JO, Ruottinen V, Ruotsalainen J, et al. Synthesis of cellulose nanocrystals carrying tyrosine sulfate mimetic ligands and inhibition of alphavirus infection. Biomacromolecules. 2014;15(4):1534-1542.

25. Hanif Z, Ahmed FR, Shin SW, Kim YK, Um SH. Size- and dose-dependent toxicity of cellulose nanocrystals (CNC) on human fibroblasts and colon adenocarcinoma. Colloids Surf B Biointerfaces. 2014;119:162-165.

26. Hosseinidoust Z, Alam MN, Sim G, Tufenkji N and van de Ven TG. Cellulose nanocrystals with tunable surface charge for nanomedicine. Nanoscale. 2015;7(40):16647-16657.

27. Eyley S and Thielemans W. Surface modification of cellulose nanocrystals. Nanoscale. 2014;6(14):7764-7779.

28. Habibi Y. Key advances in the chemical modification of nanocelluloses. Chem Soc Rev. 2014;43(5):1519-1542.

29. Hemraz UD, Sunasee R. Functionalization of Nanocrystalline Cellulose Surfaces. In Dekker Encyclopedia of Nanoscience and Nanotechnology. 3rd ed. Lyshevski SE, editors. Boca Raton, FL: CRC Press; 2014.

30. Boluk Y, Lahiji R, Zhao L, McDermott MT. Suspension viscosities and shape parameter of cellulose nanocrystals (CNC). Colloid Surf A. 2011;377(1-3):297-303

31. Hemraz UD, Boluk Y, Sunasee R. Amine-decorated nanocrystalline cellulose surfaces: synthesis, characterization and surface properties. Can J Chem. 2013;91(10):974-981.

32. Hemraz UD, Lu A, Sunasee R, Boluk Y. Structure of poly(N-isopropylacrylamide) brushes and steric stability of their grafted cellulose nanocrystal dispersions. J Colloid Interface Sci. 2014;430:157-165.
33. Lin N, Dufresne A. Supramolecular hydrogels from in situ host-guest inclusion between chemically modified cellulose nanocrystals and cyclodextrin. Biomacromolecules. 2013;14(3):871-880.

34. Zhao Q, Wang SF, Cheng XJ, Yam RC, Kong D, Li RK. Surface modification of cellulose fiber via supramolecular assembly of biodegradable polyesters by the aid of host-guest inclusion complexation. Biomacromolecules. 2010;11(5):1364-1369.

35. Deng Z, Bouchekif H, Babooram K, Housni A, Choytun N, Narain R. Facile synthesis of controlled-structure primary amine-based methacrylamide polymers via the reversible addition-fragmentation chain transfer process. J Polym Sci Part A Polym Chem. 2008;46(15):4984-4996.

36. Hemraz UD, Campbell KA, Burdick JS, Ckless K, Boluk Y, Sunasee R. Cationic poly(2-aminoethylmethacrylate) and poly(N-(2-aminoethylmethacrylamide) modified cellulose nanocrystals: synthesis, characterization, and cytotoxicity. Biomacromolecules. 2015;16(1):319-325.

37. Moya-Ortega MD, Alvarez-Lorenzo C, Concheiro A, Loftsson T. Cyclodextrin-based nanogels for pharmaceutical and biomedical applications. Int J Pharm. 2012;428(1-2):152-163.

38. Ndong Ntoutoume GMA, Granet R, Mbakidi JP, et al. Development of curcumin-cyclodextrin/cellulose nanocrystals complexes: New anticancer drug delivery systems. Bioorg Med Chem Lett. 2016;26(3):941-945.

39. Sood N, Bhardwaj A, Mehta S, Mehta A. Stimuli-responsive hydrogels in drug delivery and tissue engineering. Drug Deliv. 2016;23(3):758-780.

40. Anastasaki A, Nikolaou V, Nurumbetov G, et al. $\mathrm{Cu}(0)$-mediated living radical polymerization: a versatile tool for materials synthesis. Chem Rev. 2016;116(3):835-877.

41. Yoon HY, Koo H, Choi KY, et al. Photo-crosslinked hyaluronic acid nanoparticles with improved stability for in vivo tumor-targeted drug delivery. Biomaterials. 2013;34(21):5273-5280.

42. Yuan J, Miao C, Peng F, et al. Synthesis and characterization of poly(HPMA)-APMA-DTPA-99mTc for imaging-guided drug delivery in hepatocellular carcinoma. J Appl Polym Sci. 2013;127(6): 4549-4556.

43. van Meerloo J, Kaspers GJ, Cloos J. Cell sensitivity assays: the MTT assay. Methods Mol Biol. 2011;731:237-245.

44. van Tonder A, Joubert AM, Cromarty AD. Limitations of the 3-(4,5-dimethylthiazol-2-yl)-2,5-diphenyl-2H-tetrazolium bromide (MTT) assay when compared to three commonly used cell enumeration assays. BMC Res Notes. 2015;8:47.

45. Riss TL, Moravec RA, Niles AL, Benink HA, Worzella TJ, Minor L. Cell Viability Assays. In: Sittampalam GS, et al. Editors. Assay Guidance Manual. Bethesda MD: Eli Lilly \& Company and the National Center for Advancing Translational Sciences; 2004.

46. Lu L, Zhang L, Wai MS, Yew DT, Xu J. Exocytosis of MTT formazan could exacerbate cell injury. Toxicol In Vitro. 2012;26(4):636-644.

47. Jabbar SA, Twentyman PR, Watson JV. The MTT assay underestimates the growth inhibitory effects of interferons. Br J Cancer. 1989;60(4): 523-528.

48. Kaja S, Payne AJ, Singh T, Ghuman JK, Sieck EG, Koulen P. An optimized lactate dehydrogenase release assay for screening of drug candidates in neuroscience. J Pharmacol Toxicol Methods. 2015;73:1-6.

49. Decker T, Lohmann-Matthes ML. A quick and simple method for the quantitation of lactate dehydrogenase release in measurements of cellular cytotoxicity and tumor necrosis factor (TNF) activity. J Immunol Methods. 1988;115(1):61-69.

50. Crini G. Review: a history of cyclodextrins. Chem Rev. 2014; 114(21):10940-10975.

51. Leclercq L. Interactions between cyclodextrins and cellular components: towards greener medical applications? Beilstein J Org Chem. 2016;12:2644-2662.

52. Wick P, Manser P, Limbach LK, et al. The degree and kind of agglomeration affect carbon nanotube cytotoxicity. Toxicol Lett. 2007;168(2): 121-131.

53. Kim JE, Kim H, An SS, Maeng EH, Kim MK, Song YJ. In vitro cytotoxicity of $\mathrm{SiO}_{2}$ or $\mathrm{ZnO}$ nanoparticles with different sizes and surface charges on U373MG human glioblastoma cells. Int J Nanomedicine. 2014; 9(Suppl 2):235-241. 


\section{Supplementary materials}

Fourier transform infrared spectroscopy peak expansion of CNCs- $\beta$-CD; ${ }^{1} \mathrm{H}$ NMR and ${ }^{13} \mathrm{C}$ NMR spectra of APMA; elemental analysis of CNCs-poly(APMA).

\section{FT-IR spectroscopy of CNCs- $\beta$-CD} Elemental analysis

The percent carbon $(\mathrm{C})$, hydrogen $(\mathrm{H})$, nitrogen $(\mathrm{N})$ and sulphur (S) contents (\%) of the unmodified and cationic nanocrystalline cellulose were determined by Carlo Erba CHNS-O EA1108 Elemental Analyzer (Thermo Scientific,
Waltham, MA, USA). The remaining sample was assumed to be oxygen $(\mathrm{O})$.

\section{Nuclear magnetic resonance (NMR)}

The NMR spectra were recorded on a Bruker $400 \mathrm{MHz}$ spectrometer (Bruker, Billerica, MA, USA). The NMR data is presented as follows: chemical shift $\delta(\mathrm{ppm})$, multiplicity, coupling constant and integration. The following abbreviations were used to explain the multiplicities: $s=$ singlet, $\mathrm{d}=$ doublet, $\mathrm{t}=$ triplet. The ${ }^{1} \mathrm{H}$ NMR and ${ }^{13} \mathrm{C}$ NMR spectra were calibrated using 3-(trimethylsilyl)-1-propanesulfonic acid sodium salt $(\mathrm{TMS}=0.0)$ as the internal reference.

Table SI Elemental analysis of unmodified CNCs and CNCs-poly(APMA)

\begin{tabular}{llllll}
\hline Sample & C & H & N & S & $\mathbf{O}^{\mathbf{a}}$ \\
\hline Unmodified CNCs & 41.3 & 6.1 & 0.0 & 0.7 & 51.9 \\
CNCs-poly(APMA) & 42.0 & 6.4 & 3.1 & 0.5 & 48.0 \\
\hline
\end{tabular}

Note: ${ }^{\circ} \mathrm{O} \%=100 \%-(\% \mathrm{C}+\% \mathrm{H}+\% \mathrm{~N}+\% \mathrm{~S})$.

Abbreviations: $\mathrm{CNCs}$, cellulose nanocrystals; poly(APMA), poly(N-3-aminopropyl)methacrylamide.

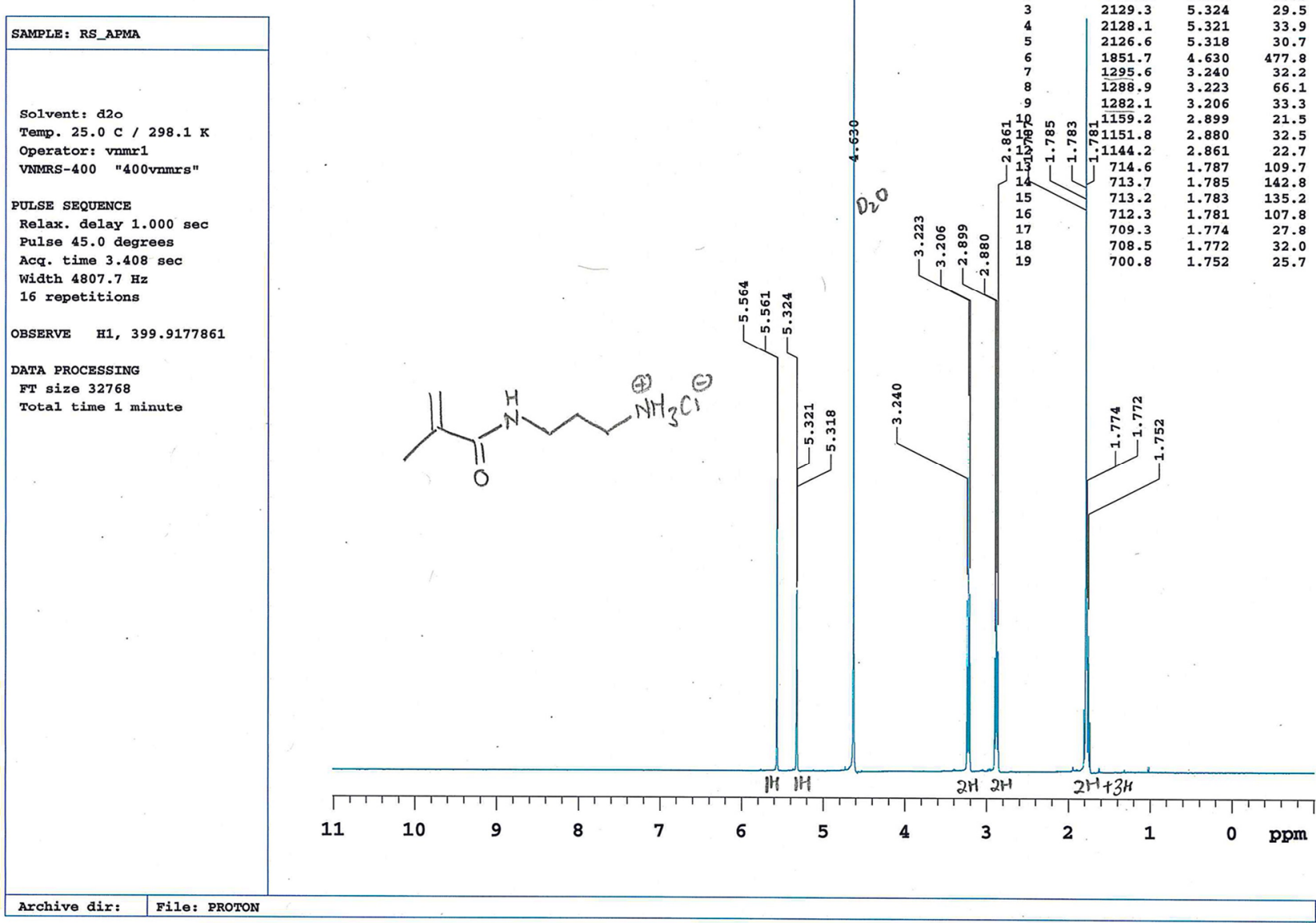

Figure SI 'H NMR of cationic monomer APMA.

Abbreviation: APMA, poly(N-3-aminopropyl)methacrylamide; 'H NMR, proton nuclear magnetic resonance. 


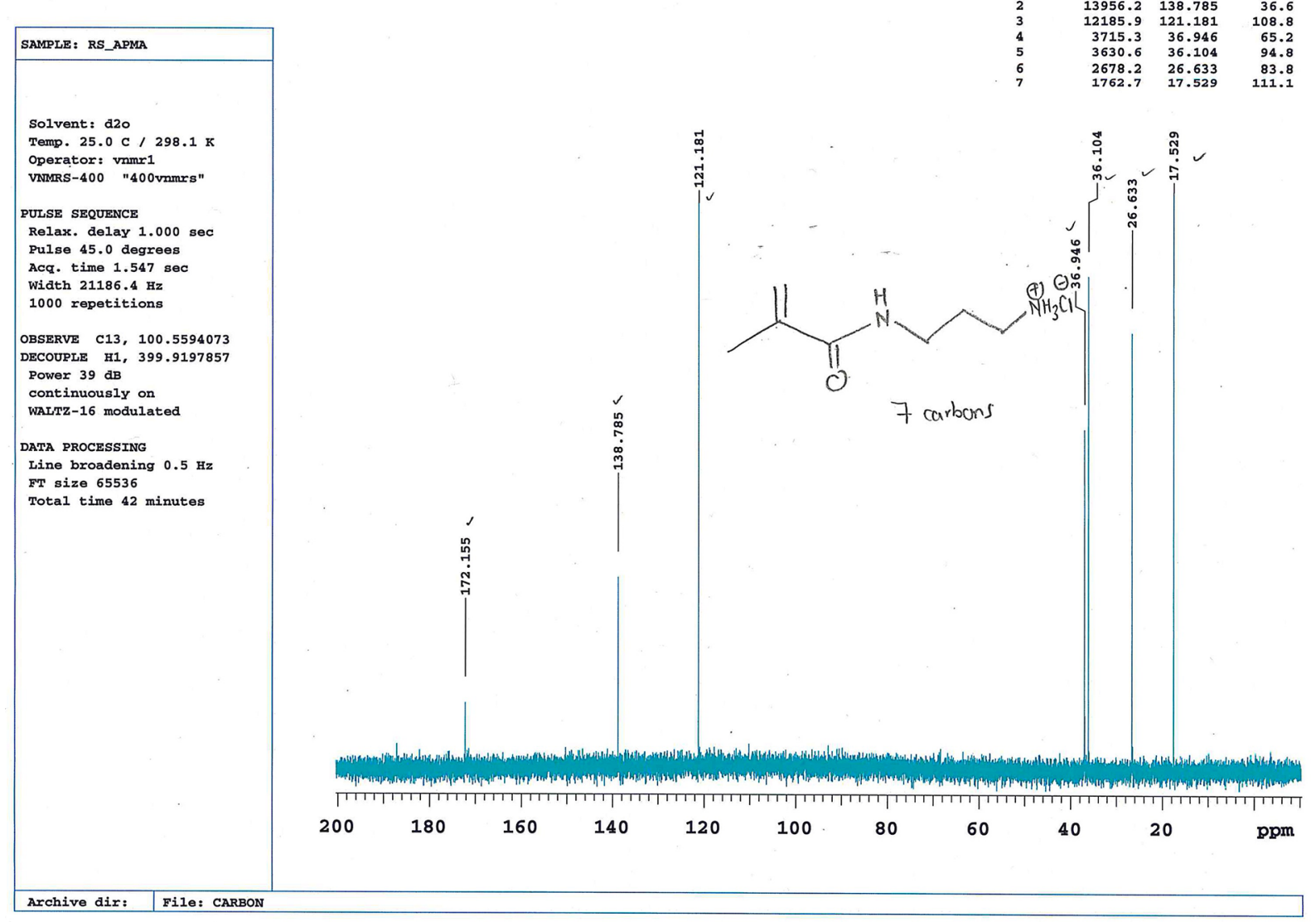

Figure S2 ${ }^{{ }^{3} \mathrm{C}} \mathrm{C} M \mathrm{R}$ data of cationic monomer APMA.

Abbreviation: APMA, poly(N-3-aminopropyl)methacrylamide; ${ }^{13} \mathrm{C}$ NMR, carbon nuclear magnetic resonance.
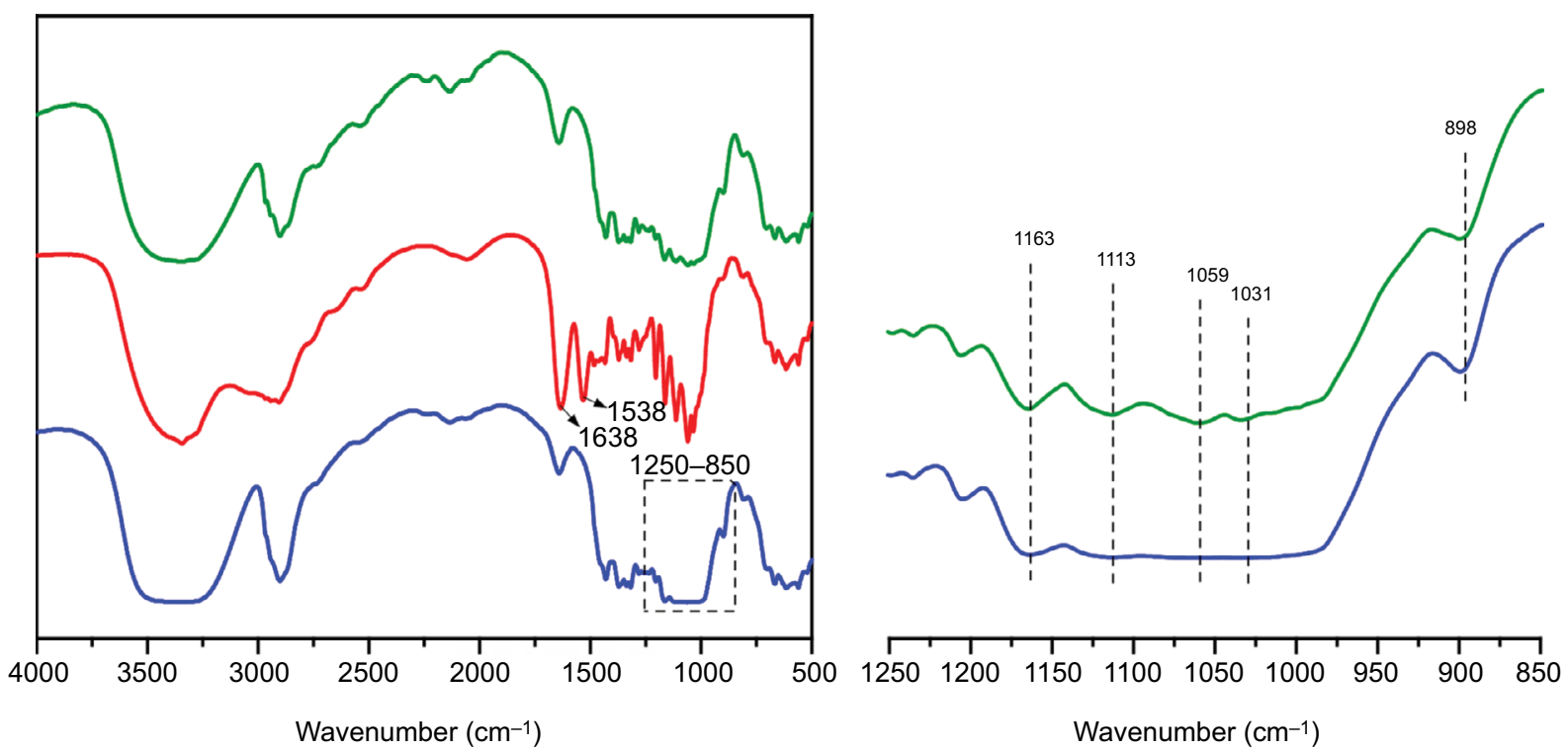

Figure S3 FT-IR of freeze-dried sample of CNCs- $\beta$-CD showing peak expansion of key peaks.

Note: Green line: unmodified CNCs, red line: CNCs-poly(APMA), blue line: CNCs- $\beta$-CD.

Abbreviations: CNCs, cellulose nanocrystals; CNCs- $\beta$-CD, CNCs grafted with $\beta$-cyclodextrin; FT-IR, Fourier transform infrared spectroscopy. 


\section{Publish your work in this journal}

Nanotechnology, Science and Applications is an international, peer-reviewed, open access journal that focuses on the science of nanotechnology in a wide range of industrial and academic applications. It is characterized by the rapid reporting across all sectors, including engineering, optics, bio-medicine, cosmetics, textiles, resource sustainability and science. Applied research into nano-materials,

particles, nano-structures and fabrication, diagnostics and analytics, drug delivery and toxicology constitute the primary direction of the journal. The manuscrip management system is completely online and includes a very quick and fair peer-review system, which is all easy to use. Visit http://www.dovepress.com testimonials.php to read real quotes from published authors.

Submit your manuscript here: https://www.dovepress.com/nanotechnology-science-and-applications-journal 